\title{
Crédito Consignado e o Risco de Endividamento: Perfil dos Servidores e o Panorama na Universidade Federal Rural de Pernambuco
}

Juliana Marçal da Silva - http://orcid.org/0000-0002-5139-0833 - julimarcal25@gmail.com ${ }^{1}$ Marcos Roberto Gois de Oliveira Macedo - http://orcid. org/0000-0002-1405-0311-marcos.gois@ufpe.br ${ }^{1}$

Resumo - O crédito consignado, espécie de operação de crédito para empréstimo pessoal, dotado de taxas de juros abaixo das praticadas pelo mercado e com cobrança das parcelas fixas mensais em folha de pagamento, representa uma alternativa atrativa para os servidores públicos. Porém, se utilizado sem o devido planejamento pode acarretar fortes impactos na vida do contratante. Diante disso, este artigo buscou fornecer um panorama acerca dos empréstimos consignados na Universidade Federal Rural de Pernambuco - UFRPE além de identificar o perfil dos servidores técnico-administrativos ativos do campus Sede da que são usuários desse crédito. Para tanto, foram analisados dados do Demonstrativo de Despesas com Pessoal, assim como aplicou-se um questionário survey com realização da estatística descritiva de frequência e tabelas de referência cruzada. Constatou-se que o (\%) da folha referente a consignação nos bancos analisados foi de 5,13\% e 3,22\%, no período de maio/2019 e novembro/2019). E que embora comprometam parcela significativa da renda com despesas, demonstraram consciência acerca do uso do crédito ao evitar o uso das modalidades tidas como mais custosas.

Palavras-chaves: Crédito Consignado; Endividamento; Servidor Público.

\section{Consigned Credit and The risk of Indebtedness: Profile of Servers and Panorama at Rural Federal University of Pernambuco}

\begin{abstract}
Payroll loans, a type of credit operation for personal loans, with interest rates below those practiced by the market and with the payment of fixed monthly installments on payroll, represent an attractive alternative for public servants. However, if used without proper planning, it can have strong impacts on the life of the contractor. In view of this, this article sought to provide a panorama about payroll loans at the Federal Rural University of Pernambuco - UFRPE in addition to identifying the profile of the active technical-administrative servants on the campus Headquarters of which are users of this credit. To this end, data from the Personnel Expenses Statement were analyzed, as well as a survey questionnaire was applied with the performance of descriptive frequency statistics and cross-reference tables. It was found that the (\%) of the payroll referring to the consignments in the analyzed banks was $5.13 \%$ and $3.22 \%$, in the period of May /2019 and November /2019). And that although they commit a significant portion of the income with expenses, they showed awareness about the use of credit by avoiding the use of the modalities considered more costly.
\end{abstract}

Keywords: Payroll Loans; Indebtedness; Public server.

Data da Submissão: 02/06/2020

Data de aceitação: 22/02/2021

DOI: $10.51359 / 2317-0115.2021 .246021$ 


\section{Introdução}

O crédito exerce um papel crucial no desenvolvimento de uma nação, tendo em vista seu potencial em proporcionar a ampliação das atividades produtivas, o incremento no poder de compra das famílias e a expansão das operações de mercado (MEDEIROS; OLIVEIRA; BENDER FILHO, 2018). Devido a sua relevância frente à economia, aliada à capacidade de possibilitar a suavização do consumo ao longo do tempo por permitir a utilização de recursos no presente esperando-se pagar com renda futura, o crédito tem sido um tema abordado em diversos estudos (FLORES, 2012; CAMPARA, VIEIRA e CERETTA, 2016; SILVA, SILVA NETO e ARAÚJO, 2017; LOPES, 2018).

Acompanhado da realidade enfrentada por uma sociedade gradativamente cada mais consumista, na qual as pessoas são estimuladas constantemente a desenvolver anseios e necessidades insaciáveis de consumo, adquirir bens, produtos ou serviços passou a figurar como status e bem-estar, de modo que conseguir equilibrar as contas tem se tornado um desafio. Nesse sentido, Lira $(2014$, p. 24) pontua que "Deve-se evitar confusão entre consumo e consumismo. $\mathrm{O}$ primeiro refere-se à satisfação das necessidades básicas do ser humano: vestir-se, alimentar-se, transporte, saúde. O consumismo, porém, é o hábito de adquirir produtos, muitas vezes desnecessários, compulsivamente".

Ademais, o desenvolvimento da tecnologia, o avanço da globalização e de novas maneiras de ofertar bens, serviços e informações acarretaram diversas alterações no mercado de crédito recente. $\mathrm{O}$ crescimento progressivo na oferta de produtos e serviços financeiros propagados por meio da publicidade agressiva dos seus fornecedores transformou as operações de crédito em uma transação de consumo comum e rotineira para os indivíduos (ALVES, 2016).

Nesse contexto, a possibilidade de desfrutar da sensação, mesmo que no curto prazo, de expandir tanto a renda disponível quanto o poder de compra visando suprir as necessidades financeiras e até mesmo consumir o que se deseja, fez com que o crédito consignado figurasse como uma opção interessante para boa parte da sociedade, sobretudo para os servidores públicos federais. Estes que tem a regulamentação da concessão do crédito consignado através da Lei 8.112 de 1990 e do Decreto 8.690 de 2016.

Diante disso, encontra-se a figura do crédito consignado, modalidade de empréstimo com custos menores e de fácil obtenção, características que tornam compreensível o fato do crédito com consignação em folha ter desempenhado papel relevante no mercado de concessão de crédito na última década. Porém, essa facilidade no acesso ao crédito consignado pode apresentar riscos se adquirido de maneira não planejada pelos usuários (BCB, 2018).

Soares, Cavalhero e Trevisan (2017) pontuam que essa facilidade de contratação associada às políticas de ampliação de crédito ocasiona, em muitos momentos, um endividamento em excesso, que compromete parte significativa da renda dos servidores, provocando impacto negativo sobre a qualidade de vida, condição psicológica, estabilidade social e a capacidade laboral dos indivíduos.

Em paralelo a isso, Flores (2012, p.15) salienta que "uma das consequências negativas do endividamento é a probabilidade de inadimplência do consumidor". Fato que pode ser evi- 
denciado a partir do levantamento desenvolvido mensalmente pela Confederação Nacional do Comércio de Bens, Serviços e Turismo (CNC), que representa a Pesquisa de Endividamento e Inadimplência do Consumidor (PEIC), referente ao mês de setembro de 2019, em que foi constatado que o percentual de famílias com dívidas aumentou pelo nono mês consecutivo em 2019, alcançando $65,1 \%$ do total, sendo o maior patamar desde julho de 2013 e o terceiro maior resultado da série histórica. O cartão de crédito foi apontado como o principal tipo de dívida $(79,5 \%)$ pelas famílias endividadas, seguido por carnês $(15,5 \%)$, financiamento de carro $(9,7 \%)$, financiamento de casa $(8,8 \%)$ e crédito pessoal $(8,4 \%)$.

Revelando um cenário que corrobora a preocupação com o endividamento, especialmente com o contexto brasileiro, que se explica em função do percentual de famílias nesta situação ser elevado (PACHECO; CAMPARA; COSTA JR, 2018. Sendo esse entendimento ratificado por Vieira, Flores e Campara (2014, p. 201) ao afirmarem que "o número de famílias endividadas vem crescendo no Brasil”.

Frente a isso, cabe destacar a situação dos servidores públicos, uma vez que estes são os maiores usuários do crédito consignado, correspondendo em março de 2018 , a 56,2\% do total de tomadores. Ao passo que, ao fazer uma comparação com a evolução dos valores (R\$) contratados na última década, foi constatado que em março de 2008 os servidores possuíam R \$ 59 bilhões em dívidas com empréstimo consignado; já em março de 2018, esse montante foi triplicado, chegando à importância de R\$ 178 bilhões (ACORDI, 2019).

Sendo pertinente salientar que esse cenário se refere a uma realidade anterior à chegada da pandemia de Covid-19, emergência de saúde pública que vem acarretando impactos devastadores a nível mundial, cujos fortes efeitos já são sentidos na economia nacional e tem levado a alterações drásticas nas previsões e estimativas dos gastos.

Ressaltando que até pouco tempo antes desse surto, o Brasil possuía um cenário de inflação controlada, com estimativa de 3,5\% a.a., mas que com o advento do novo Coronavírus foi ajustada para o patamar de $2,0 \%$ a.a. Registrando em maio/2020, uma queda de $0,59 \%$ no Índice Nacional de Preços ao Consumidor Amplo 15 (IPCA-15), a maior deflação desde o início do Plano Real, em julho de 1994 e a segunda deflação seguida do IPCA-15, que enfrentou $-0,01 \%$ em abril/2020 (IBGE, 2020). Situação semelhante ocorreu com o PIB após registrar uma redução da expectativa de crescimento de $2,1 \%$ para $0,0 \%$ (zero) já no início da pandemia em março/2020, com perspectiva mais recente, realizada em maio/2020, de queda de cerca de $4,7 \%$ até o fim do ano de 2020 .

Também foram registrados cortes da taxa Selic, atingindo 3,0\%, o menor patamar da história e seguindo com previsão de corte de $0,75 \%$ na próxima reunião do COPOM. A desvalorização do real também vem sendo sentida fortemente, com o dólar atingindo a cotação recorde de R \$ 5,90 no início de maio/2020. Fatores que convergem para um horizonte em que o que o crédito torna-se mais caro em decorrência do aumento do risco de inadimplência que a instabilidade vem causando (BCB, 2020).

Desse modo, verifica-se o delineamento de um cenário que exigirá ainda mais atenção quanto ao planejamento orçamentário, não apenas do Estado mas também das famílias, frente às dificuldades que serão impostas na conjuntura pós-pandemia, uma vez que se desenha uma tendência de recessão econômica e ações destinadas a evitar o endividamento serão de relevante importância. Assim, pesquisas desenvolvidas no âmbito das universidades federais em relação 
ao uso do crédito consignado e o efeito do endividamento dos servidores públicos constituem ferramenta importante acerca da importância do bom planejamento dos recursos financeiros (SOUZA, 2015; ALVES, 2016; LEÃO, 2016; LOPES, 2018; ACORDI, 2019).

Constituindo um fator responsável por suscitar o interesse em compreender melhor como o servidor, sobretudo os Técnicos Administrativos em Educação (TAEs) da Universidade Federal Rural de Pernambuco (UFRPE), campus Sede/Dois Irmãos, tem se comportado financeiramente em meio a essa complexa realidade.

Diante disso, um dos objetivos do presente estudo consiste em traçar o perfil dos servidores técnico-administrativo usuários do crédito, sobretudo do crédito consignado na UFRPE, a partir da aplicação de um questionário estruturado (survey) e tomando como base aspectos do estudo de Flores (2012), no qual verificou-se a relação entre os traços demográficos representados pelas variáveis: idade, gênero, raça, escolaridade, estado civil, composição da família e situação da residência com a situação de endividamento. Já o segundo objetivo se propõe a fornecer um panorama sobre o empréstimo consignado no âmbito da UFRPE, sendo alicerçado em dados fornecidos pela instituição, extraídos do Demonstrativo de Despesas com Pessoal (DDP) nos meses de maio/2019 e novembro/2019.

Cabendo destacar a relevância em pesquisar acerca do tema, uma vez que foi verificado que em diversas universidades o número de servidores com empréstimo consignado é bastante significativo. Salientando que os resultados dessa pesquisa poderão servir de base para outros estudos e até como ferramenta para o incremento na oferta de cursos de capacitação na área de Educação Financeira destinados aos servidores.

\section{Crédito Consignado: Definições, Origem e o Risco de Endividamento}

O crédito consignado pode ser entendido como "uma modalidade de empréstimo em que o desconto da prestação é feito diretamente na folha de pagamento ou de benefício previdenciário do contratante" (BANCO CENTRAL DO BRASIL, 2018, p. 110). Ao passo que Lira (2014) define o empréstimo consignado como uma opção interessante para o trabalhador, devido à baixa taxa de juros e a garantia de inadimplência quase zero. E uma definição mais técnica afirma que "As consignações em folha de pagamento são descontos mensais processados nos contracheques dos servidores ativos, aposentados e beneficiários de pensão do Poder Executivo Federal, através do Sistema SIAPE e se dividem em compulsórias ou facultativas", conforme Portaria Normativa nº 1/2010-MPOG/SRH.

Frisando que tal consignação em folha de pagamento ou em benefício é limitada à margem consignável disponível, condicionada tanto à autorização prévia e expressa do contratante junto à instituição financeira que concederá o empréstimo como à validade do convênio entre a fonte pagadora e a instituição que oferta a operação.

Quanto a sua origem, o processo de tomada de recursos via empréstimos pelos servidores públicos teve seu início nas leis brasileiras com o Decreto-Lei n. ${ }^{\circ}$ 9.790/1946 e, posteriormente, com a Lei $\mathrm{n}^{\mathrm{o}} 1.046 / 1950$, que tratava da consignação em folha de pagamento dos funcionários 
públicos em geral. Alguns anos depois, foi publicada a Lei n. ${ }^{\circ}$ 6.445/1977, normatizando as consignações em folha de pagamento de servidores civis, ativos e inativos da Administração Federal direta e das autarquias federais.

O Art. 45 da Lei no . 8.112/90 (que dispõe sobre o Regime Jurídico Único dos servidores públicos civis da União, das autarquias e das fundações públicas federais) foi alterado pela Lei $\mathrm{n}^{\mathrm{o}}$. 13.172/15, em seu Art. $3^{\circ}$, passando a vigorar o seguinte texto:

$\S 1^{\circ}$. Mediante autorização do servidor, poderá haver consignação em folha de pagamento em favor de terceiros, a critério da administração e com reposição de custos, na forma definida em regulamento.

$\S 2^{\circ}$. O total de consignações facultativas de que trata o $\S 1^{\circ}$ não excederá a $35 \%$ (trinta e cinco por cento) da remuneração mensal, sendo 5\% (cinco por cento) reservados exclusivamente para:

I - a amortização de despesas contraídas por meio de cartão de crédito; ou

II - a utilização com a finalidade de saque por meio do cartão de crédito. (BRASIL, 1990, Lei 8.112/1990, Art. 45).

Pontuando que a Lei $\mathrm{n}^{\mathrm{o}} 13.172 / 15$ alterou tanto a Lei $\mathrm{n}^{\circ}$ 8.112/90, quanto as Leis $\mathrm{n}^{\circ}$. 8.213/91 e a Lei $\mathrm{n}^{\mathrm{o}}$. 10.820/03, no que tange ao desconto em folha de pagamento de valores direcionados ao pagamento de cartão de crédito. Estabelecendo o mesmo limite de $35 \%$ para desconto do benefício ou remuneração, sendo os 5\% destinados exclusivamente para o pagamento de despesas advindas de cartão de crédito ou destinadas para o saque através do cartão de crédito.

Assim como o Decreto nº 8.690/2016 da Presidência da República que dispõe sobre a gestão das consignações em folha de pagamento no âmbito do sistema de gestão de pessoas do Poder Executivo Federal. Nele destaca-se o estabelecimento do limite de 96 parcelas para descontos de consignações e a determinação do percentual máximo permitido de $35 \%$ do valor da remuneração, do subsídio, do salário, do provento ou da pensão do consignado, no qual os $5 \%$ devem ser reservados exclusivamente para amortização de despesas contraídas no cartão de crédito ou para realizar saques por meio dele.

Ademais, além da espécie de crédito conhecida como empréstimo consignado, "Existem várias modalidades de crédito, por exemplo: limite do cheque especial, cartão de crédito, empréstimos, financiamentos imobiliários ou de veículos, compra a prazo em lojas comerciais" (BCB, 2013, p. 25). E dentre estas opções mais usuais, destaca-se o cartão de crédito, nas modalidades à vista e parcelado lojista, (sem juros das instituições financeiras) como o produto de crédito mais utilizado pelos brasileiros. Acompanhada da modalidade de crédito conhecida como crédito consignado que tem contabilizado uma parcela cada vez maior de usuários no serviço público diante do cenário econômico atual (ACORDI, 2019). 
Frente a isso, é fundamental ter em mente que os produtos de crédito devem ser adequados ao perfil de cada consumidor, assim como estar atreladas às suas necessidades específicas e à capacidade de pagamento de cada pessoa, segundo o Relatório de Estabilidade Financeira do Banco Central do Brasil (2018), assim define:

O crédito pode ser um excelente instrumento de suavização de consumo ao longo do tempo, pois possibilita a utilização de recursos no presente, esperando-se pagar com renda futura. No entanto, é importante que seja utilizado de forma sustentável. Quando isso não acontece, os níveis de endividamento e comprometimento da renda ultrapassam o limite do que é financeiramente gerenciável, levando à inadimplência. (BCB, 2018, p. 30).

Nota-se que a concessão de crédito permite que se antecipe o uso do dinheiro, sendo utilizado no presente um valor que só estaria disponível no futuro. Sendo assim, compreende-se que "o crédito consignado não é um adicional da renda familiar e sim uma maneira de se conseguir dinheiro para satisfazer alguma necessidade ou desejo" (LOPES, 2018, p. 41).

Alves (2016) observa que em meio ao contexto de facilidades na concessão de crédito sem que haja a checagem da saúde financeira do tomador, especialmente dos servidores públicos, associado ao implacável apelo ao consumo, criou-se um processo de endividamento, desencadeando muitas vezes, a falência civil dos servidores.

Desse modo, o acesso ao crédito pode representar para os trabalhadores uma oportunidade de adquirir bens e serviços que os salários não seriam capazes de proporcionar. Mas, um dos principais impactos dos empréstimos na vida dos indivíduos é a ocorrência de um vasto processo de endividamento, que resulta no comprometimento de parcela relevante da renda com a quitação de empréstimos e dos juros (MOURA; OLIVEIRA; SILVA, 2018).

Nesse sentido, cabe destacar que as variáveis demográficas como gênero, idade, nível de escolaridade, número de membros da família e os fatores demográficos, tais como renda, taxa de juros e emprego possuem uma relação muito tênue com os níveis de endividamento (BONOMO; MAINARDES; LAURETT, 2017). Nesse contexto, Pacheco, Campara e Costa Jr. (2018) assinalam que o comportamento diante do endividamento é suscetível a ser influenciado por traços do perfil dos indivíduos. E que as variáveis: sexo, idade, escolaridade, estado civil, renda, moradia, ocupação, quantidade de dependentes representam algumas dessas possíveis relações.

Compreendendo, portanto, que o processo de endividamento pode ser entendido a partir de aspectos comportamentais baseados em questões demográficas próprias de cada indivíduo, como se observa no estudo de Ponchio (2006), que constatou a relação entre o endividamento e fatores como gênero, idade e escolaridade, demonstrando, por exemplo, que indivíduos mais velhos apresentam menor probabilidade de assumir dívidas. Constituindo assim, fatores e relações que serão analisadas no presente estudo. 


\section{Gestão da Folha de Pagamento da UFRPE e o Crédito Consignado}

A Universidade Federal Rural de Pernambuco é uma instituição com 107 anos de tradição em ensino, pesquisa e extensão em âmbito estadual e nacional. Possui em sua história secular a capacidade de inovação, em decorrência de procurar contribuir com a superação dos problemas socioambientais quanto com o desenvolvimento sustentável.

Desde sua criação, em 1912, até hoje, a UFRPE tem alcançado bons resultados em expansão, possuindo em sua estrutura além da sede, localizada no bairro de Dois Irmãos Recife, a Unidade Acadêmica de Serra Talhada (UAST), Unidade Acadêmica do Cabo de Santo Agostinho (UACSA), a Unidade de Educação a Distância (UEADTec) e a Unidade Acadêmica de Garanhuns (UAG), desmembrada da UFRPE em 2018, dando início à Universidade Federal do Agreste de Pernambuco (UFAPE). Conta ainda com estações avançadas de pesquisa, ou seja, campi situados no Litoral, na Zona da Mata, no Agreste e no Sertão de Pernambuco.

Ao longo do tempo a UFRPE foi se expandindo e atualmente conta com 59 cursos de graduação, na pós-graduação, destacam-se 44 programas, que ofertam 62 cursos de Pósgraduação stricto sensu, também oferta Ensino Médio e cursos técnicos no Colégio Agrícola Dom Agostinho Ikas (CODAI).

No que tange ao corpo técnico especializado, a UFRPE é composta por mais de 1.200 professores, um corpo de técnicos superior a 1.000 servidores e cerca de 17.000 estudantes. Engloba 22 departamentos acadêmicos na sede em Dois Irmãos, com cerca de 1.561 servidores, além dos integrantes das suas Unidades Acadêmicas e do colégio de nível médio/técnico, o Colégio Agrícola Dom Agostinho Ikas (CODAI) com suas estações e bases experimentais, contando assim com um total de 2.348 servidores, de acordo com o Relatório de Gestão (UFRPE, 2018).

Nesse contexto, a exemplo das demais instituições públicas da Administração direta, fundações e autarquias, a UFRPE também está inserida na gestão das consignações em folha de pagamento no âmbito do Sistema de Gestão de Pessoas do Poder Executivo Federal (SIGEPE), uma vez que a folha de pagamento de seus servidores, aposentados e pensionistas é processada pelo Sistema Integrado de Administração de Pessoal (SIAPE) do Poder Executivo Federal.

Desse modo, a folha de pagamento da UFRPE abrange todas as despesas mensais com pagamento de servidores ativos, aposentados, pensionistas, cargos comissionados, contratos temporários (professores substitutos, visitantes), médicos residentes e residência multiprofissional, além dos estagiários.

Integram a folha de pagamento os gastos com benefícios sociais, a exemplo dos auxílios: alimentação, transporte, pré-escolar e a saúde suplementar, o chamado (per capita); como também os descontos compulsórios: contribuição para o plano de seguridade social do servidor público, imposto de renda retido na fonte, contribuição para a previdência social, pensão alimentícia judicial, reposição ao erário, obrigações decorrentes de decisões judiciais ou administrativas além dos descontos facultativos, a exemplo da: contribuição para plano de saúde, pensão alimentícia voluntária ou contribuição para sindicatos, segundo o Decreto nº 8.690/2016. 
Através do Sistema de Gestão de Pessoas - SIGEPE, sistema do Governo Federal referente a questões de pessoal, servidores, aposentados e pensionistas podem acessar e realizar operações como: verificar prévia do contracheque, consultar margem consignável e gerar autorização de consignatária. O acesso ao sistema "SIGEPE Servidor e Pensionista" ocorre pelo Portal do Servidor, com a utilização de certificado digital (token) e mediante senha de uso pessoal e intransferível, ou pelo aplicativo SIGEPE Mobile. Para obter o acesso ao SIGEPE, o usuário deverá cadastrar a senha no SIGAC (Sistema de Gestão de Acesso), seguindo as instruções do Primeiro Acesso. Por sua vez, o processo de cadastramento das consignatárias no SIGEPE estará sujeito ao cumprimento das condições estabelecidas para que possam atuar junto aos órgãos públicos.

Como procedimento padrão, os valores das consignações deverão ser repassados às empresas consignatárias pelos órgãos e entidades integrantes do Sistema de Pessoal Civil da Administração Federal (SIPEC) e por aqueles cujas folhas de pagamento sejam processadas pelo SIGEPE, até o quinto dia útil do mês subsequente ao do processamento da folha de pagamento, de acordo com a Portaria no . 110/2016.

Caso haja alguma divergência no processo de consignação, o Sistema de Gestão de Pessoas do Poder Executivo Federal possui o módulo de Apuração de Irregularidades destinado ao registro e tratamento automatizado das reclamações de irregularidade no processo de consignação, imprimindo maior celeridade e transparência nos procedimentos e no processo de apuração das reclamações administrativas efetuadas pelos servidores e pensionistas.

A partir do Quadro 2 é possível comparar os dados obtidos nesta pesquisa em relação aos 3 principais bancos em volume de recursos com as informações encontradas por Leão (2016) e assim acompanhar a evolução dos valores de consignações em folha de pagamento no âmbito da UFRPE.

Quadro 2 - Instituições Financeiras e os valores em R\$ em consignação na UFRPE

\begin{tabular}{|l|c|c|c|c|c|}
\hline \multirow{2}{*}{ Instituições Financeiras } & \multicolumn{5}{|c|}{ Folha de Pagamento } \\
\cline { 2 - 6 } & Maio/2012 & Maio/2013 & Maio/2014 & Maio/2015 & Maio/2020 \\
\hline Banco do Brasil S/A & $271.323,93$ & $531.408,40$ & $580.596,18$ & $632.311,07$ & $949.433,64$ \\
\hline $\begin{array}{l}\text { Caixa Econômica Fe- } \\
\text { deral }\end{array}$ & $207.350,36$ & $267.612,36$ & $314.952,88$ & $340.362,98$ & $441.753,44$ \\
\hline Banco BMG/Itaú S/A & $309.418,07$ & $376.756,96$ & $328.483,02$ & $424.192,45$ & $211.762,03$ \\
\hline $\begin{array}{l}\text { Valor total das consigna- } \\
\text { tárias }\end{array}$ & $986.931,58$ & $1.459 .739,90$ & $1.747 .381,52$ & $1.877 .472,48$ & $1.962 .673,28$ \\
\hline
\end{tabular}

Fonte: elaborado pela pesquisadora, adaptado de Leão (2016).

Demonstrando um incremento tanto no valor das consignações das instituições financeiras analisadas, como do valor total tomado em crédito consignado pelos servidores da UFRPE, com exceção do Banco BMG/Itaú S/A que apresentou períodos alternados entre aumento e diminuição do valor contratado pelos servidores. 


\section{Estratégia Metodológica}

Este estudo se propõe a traçar o perfil dos servidores Técnico-Administrativos em Educação (TAE) efetivos da UFRPE integrantes do campus Sede, usuários do crédito, sobretudo do crédito consignado, além de fornecer um panorama acerca dos empréstimos consignados contratados por estes servidores. Para tanto, analisou-se o Demonstrativo de Despesas com Pessoal (DDP) nos meses de maio/2019 e novembro/2019.

A escolha do mês de maio/2019 foi oriunda da situação de bloqueios significativos no orçamento das universidades, sobretudo da UFRPE que sofreu um corte em torno de $30 \%$, o que desencadeou o princípio das incertezas quanto ao adequado cumprimento do planejamento das atividades (UFRPE, 2019). Já o mês de novembro/2019 representa um balanço acerca das alterações ocorridas no primeiro ano do novo governo Bolsonaro, em que a situação do servidor público federal veio à tona inúmeras vezes, além de ser o mês que a reforma da previdência foi concretizada, trazendo mudanças para o futuro laboral dos servidores.

Através da organização e tabulação dos dados no software Microsoft Excel 2010, foi possível fornecer um panorama com informações sobre o total de servidores no período 20162019; o quantitativo de servidores classificados por categoria funcional (ativos, aposentados e pensionistas); a evolução da folha de pagamento da instituição nos meses de maio/2019 e nov/2019; o valor (R\$) das consignações constantes nos 9 bancos com maior volume de recursos utilizados para empréstimos consignados nos meses citados, além de identificar o percentual da renda dos servidores que encontra-se comprometida com despesas de crédito consignado.

Também foi delineado o perfil sociodemográfico da amostra, sua dependência de crédito, assim como verificou-se o percentual de servidores que são dependentes do crédito consignado, de acordo com as características de perfil apresentadas.

A população da pesquisa englobou todos os servidores técnico-administrativos ativos lotados no campus Recife/PE, totalizando 838 servidores. A amostra não-probabilística, foi definida através do critério de acessibilidade, totalizando 263 servidores, com o regresso de 185 respostas válidas, o que corresponde a $70 \%$ da amostra pesquisada e $22,08 \%$ de taxa de retorno. Destacando que a classe dos docentes (714 servidores) não foi incluída na pesquisa pelo fato de essa categoria ter tido um acordo de reajuste que vigorou até agosto/2018 juntamente com o pagamento da última parcela de aumento, enquanto a categoria dos técnico-administrativos (838 servidores) seguem como a classe que está há mais tempo sem nenhuma espécie de ganho.

A técnica de coleta de dados utilizada se deu por meio de uma pesquisa survey com a aplicação de um questionário estruturado. Composto por 13 questões, divididas em 2 blocos, conforme explicitado no Quadro 3. O primeiro bloco engloba perguntas relativas ao perfil sociodemográfico do servidor, possui 9 questões referentes aos aspectos de gênero, idade, estado civil, quantidade de dependentes econômicos, situação de moradia, grau de escolaridade, raça, tempo de serviço e renda familiar, e o segundo bloco atinente ao perfil de uso do crédito, com 4 questões sobre utilização do cartão de crédito, forma como as despesas costumam ser pagas, percentual da renda comprometido com quitação de despesas de crédito e uso do cheque especial para gastos cotidianos, baseadas em aspectos do estudo de Flores (2012) e de Lopes (2018). 
Quadro 3 - Síntese do instrumento de coleta de dados - questionário

\begin{tabular}{|c|c|c|c|}
\hline Bloco & Tema & Variáveis & Referências \\
\hline \multirow{9}{*}{1} & \multirow{9}{*}{$\begin{array}{c}\text { Perfil do } \\
\text { servidor(a), } \\
\text { analisado } \\
\text { a partir de } \\
\text { variáveis sociais } \\
\text { e demográficas }\end{array}$} & Gênero (Q1) & Elaborado pela autora \\
\hline & & Faixa etária $(\mathrm{Q} 2)$ & Classificação IBGE \\
\hline & & Estado civil (Q3) & Classificação IBGE \\
\hline & & Quantidade de dependentes (Q4) & Elaborado pela autora \\
\hline & & Moradia $(\mathrm{Q} 5)$ & Elaborado pela autora \\
\hline & & Grau de escolaridade (Q6) & Classificação IBGE \\
\hline & & Raça $(\mathrm{Q} 7)$ & Classificação IBGE \\
\hline & & Tempo de serviço UFRPE (Q8) & Elaborado pela autora \\
\hline & & Faixa de renda familiar (Q9) & Classificação IBGE \\
\hline \multirow{4}{*}{2} & \multirow{4}{*}{$\begin{array}{l}\text { Perfil do } \\
\text { servidor(a) } \\
\text { quanto à } \\
\text { variável uso do } \\
\text { crédito }\end{array}$} & Pagamento das despesas (Q10) & Leão (2016) \\
\hline & & Uso do cartão de crédito (Q11) & Flores (2012) \\
\hline & & (\%) Renda líq. no cartão (Q12) & Flores (2012) \\
\hline & & Uso do cheque especial (Q13) & isney e Gathergood (201 \\
\hline
\end{tabular}

Fonte: elaborado pela autora, adaptado de Flores (2012).

A coleta de dados ocorreu entre os dias 07 e 26 do mês de abril de 2020, a partir da plataforma de formulários do Google, sendo compartilhada via e-mail institucional de cada servidor e também por meio de aplicativo de mensagens, WhatsApp, com a realização de duas tentativas de contato com os servidores, com um intervalo de 10 dias entre elas. Foi precedida da realização do pré-teste, aplicado no mês de março de 2020, com 10 participantes selecionados que apontaram sugestões e melhorias para a versão final, assim como contribuíram para validar as questões. Cabe ressaltar que em virtude da pandemia do novo Coronavírus e da obrigatoriedade de cumprir o isolamento social, não foi possível utilizar a forma presencial de coleta de dados, proposta inicialmente no estudo.

Para organização e análise dos dados foi utilizado o software Microsoft Excel 2010 e o software IBM SPSS Statistics, no qual foram estimadas as estatísticas descritivas de frequência e tabela de referência cruzada, com base nas medidas de tendência central, média e soma, medidas de posição, frequência absoluta e relativa e o percentual válido das variáveis. Ressaltando que não se buscou identificar cada respondente, apenas coletar informações suficientes para atender aos objetivos da pesquisa.

\section{Análise dos Resultados: Perfil dos Servidores usuários do Crédito Consigna- do e Panorama na UFRPE}

Com o intuito de caracterizar a amostra e descrever o perfil dos participantes que fazem uso do crédito consignado, coletou-se informações acerca de variáveis como idade, gênero, escolaridade, estado civil, moradia, tempo de serviço e renda familiar, além de características concernentes ao perfil de uso do crédito pelos servidores, como informações acerca dos meios de pagamento mais utilizados com gastos corriqueiros e uso do cartão de crédito e cheque especial. 
Perfil da amostra a partir de Variáveis Sociais e Demográficas

Em relação ao gênero, nota-se que dentre os 185 participantes da pesquisa, a maioria dos respondentes $(60,5 \%)$ pertence ao sexo feminino, mas em relação a dependência do crédito consignado, embora represente maioria, as mulheres dizem depender menos de consignação $(17,3 \%)$ do que os homens (39,5\%). No que tange à idade, identificou-se que a faixa etária com o maior número de participantes compreende o intervalo de 35 a 44 anos $(37,3 \%)$, sendo a idade mínima identificada de 23 anos e a idade máxima de 74 anos e que dentre os participantes que disseram utilizar o crédito consignado, os percentuais diminuíram com a elevação da idade.

Quanto ao estado civil, mais da metade dos servidores participantes $(51,4 \%)$ é casado(a), e também representam maioria quanto à dependência do crédito $(42,2 \%)$. Já em relação ao número de dependentes econômicos, que podem ser filhos, cônjuge ou qualquer outra pessoa que dependa financeiramente do respondente, verificou-se que $61,1 \%$ do total de servidores tem algum tipo de dependente da sua renda, com destaque para o mesmo percentual $(26,5 \%)$ que possui 1 ou 2 dependentes, ressaltando que a totalidade deste último grupo afirmou depender do crédito consignado, revelando que os servidores exercem um papel importante na renda de suas famílias.

No que diz respeito ao tipo de moradia, a maioria dos servidores afirmou ter casa própria (39,5\%) e não depender do crédito consignado, sinalizando uma característica de perfil mais conservador que preza pela segurança dos familiares. Entretanto, cabe destacar a relativa proximidade entre os servidores que moram de aluguel (33,5\%) e dependem do crédito consignado (29,7\%). Corroborando o estudo de Flores (2012) no qual foi demonstrado que os proprietários de imóveis possuíam maior percepção de risco financeiro, estando menos propícios a fazer novas dívidas.

Quanto ao grau de escolaridade, observou-se que praticamente metade dos servidores (49,7\%) possui especialização e aqueles que detém maior grau de escolaridade representam os que fazem uso da consignação em folha de pagamento: $26,5 \%$ especialização; $27,0 \%$ mestrado e $3,2 \%$ doutorado. O que evidencia que um alto grau de instrução influencia no nível de tolerância de endividamento, podendo fazer a diferença na utilização do crédito consignado.

Com relação à raça, a maior parte dos participantes se definiu como pertencente a raça branca $(44,9 \%)$ formada de um quantitativo bastante significativo $(43,2 \%)$ que afirmou não depender do crédito consignado, demonstrando que as pessoas da raça branca apresentaram uma noção maior de endividamento e percepção de risco em relação aos demais. Uma vez que os participantes pardos registraram um percentual bastante próximo $(42,7 \%)$ e em sua totalidade admitiram utilizar o empréstimo em consignação.

Acerca do tempo de serviço, observou-se que os participantes possuem uma média de 8 anos de trabalho, com um desvio padrão de 1,660 e aqueles que têm entre 5 e 10 anos de trabalho foram maioria (37,3\%), seguidos pelos respondentes com mais de 20 de contribuição. Demonstrando que a instituição passou um período sem realizar concursos e que recentemente, com advento de novas unidades, sua mão-de-obra vem sendo renovada. 
No que tange à dependência do crédito consignado quanto ao tempo de serviço, verificou-se que os servidores mais recentes na instituição, nas faixas até 10 anos de trabalho, afirmaram não utilizar esse tipo de crédito: $14,6 \%$ ( 0 a 3 anos); 11,9\% (3 a 5 anos) e 16,8\% (5 a 10 anos), respectivamente. Salientando que os respondentes mais antigos na instituição, com mais de 20 anos de serviço, se destacaram na dependência do crédito com consignação em folha de pagamento $(22,2 \%)$, o que sugere tratar-se de um hábito mais usual entre os mais antigos, seja pela cultura de comodidade em contrair um novo empréstimo ou pelo aumento das despesas com a idade e o salário proporcionalmente não acompanhar essa evolução.

Analisando a renda mensal familiar dos respondentes, identificou-se que boa parte (31,9\%) recebe entre 3 e 5 salários mínimos, o que significa entre $\mathrm{R} \$ 3.136,00$ e $\mathrm{R} \$ 5.225,00$, e concomitantemente, apresentaram ausência de dependência do crédito (31,9\%). Ao passo que, verificou-se que os servidores com as maiores rendas mensais no âmbito familiar foram os que afirmaram utilizar o crédito consignado, com destaque para a faixa entre 6 e 8 salários mínimos ( R \$ 6.271,00 a R \$ 8.360,00) em que 17,3\% afirma depender do crédito consignado. Realidade que não corrobora com a ideia de que as menores faixas salariais costumam ser mais dependentes do crédito e propensas ao endividamento.

Perfil dos Servidores quanto ao uso do Crédito e Endividamento

O perfil dos servidores foi traçado com base de 4 questões que trataram dos meios de pagamento das dívidas, uso do cartão de crédito, percentual de renda líquida comprometida com cartão de crédito e uso do cheque especial e do limite do cartão de crédito, adaptadas do estudo de Flores (2012) e Leão (2016).

Em relação à maneira como os respondentes pagam suas contas a grande maioria (39,54\%) tem no cartão de débito a forma mais usual, seguido do cartão de crédito $(35,62 \%)$, com a opção em dinheiro ficando praticamente na última posição $(24,51 \%)$, visto que apenas um participante mencionou quitar despesas em cheque (0,33\%). Cenário que pode ser explicado com base em dados da Associação Brasileira de Empresas de Cartões de Crédito e Serviços (ABECS) em 2019, que revelam que as compras feitas com cartões de débito, de crédito e pré-pagos cresceram 17\% no primeiro trimestre de 2019.

Tabela 1 - Meio de pagamento das despesas

\begin{tabular}{l|c|c}
\hline Meio de Pagamento & Frequência (N) & Percentual (\%) \\
\hline Em dinheiro & 75 & 24,51 \\
\hline Cartão de débito & 121 & 39,54 \\
\hline Cartão de crédito & 109 & 35,62 \\
\hline Cheque & 1 & 0,33 \\
\hline
\end{tabular}

Fonte: dados da pesquisa, adaptado de Leão (2016).

Quanto ao uso do cartão de crédito, verificou-se que a quase a totalidade de servidores afirmou fazer uso do cartão de crédito (91,9\%). Dentre eles estão os que utilizam apenas 1 cartão (39,5\%), seguidos dos que possuem 2 cartões (37,3\%) e por fim os participantes que têm 
3 ou mais cartões de crédito $(15,1 \%)$. Fato que merece destaque em virtude de a Confederação Nacional do Comércio de Bens, Serviços e Turismo (CNC), que representa a Pesquisa de Endividamento e Inadimplência do Consumidor (PEIC) ter constatado que o cartão de crédito representa o principal tipo de dívida $(79,5 \%)$ pelas famílias endividadas brasileiras, conforme Tabela 2.

Com destaque para os respondentes que possuem 2 cartões e afirmam depender do crédito consignado (37,3\%) e os que detém 3 ou mais cartões e se dizem usuários do crédito consignado $(15,1 \%)$. Fato que sugere a relação entre o uso do cartão de crédito e a contratação de empréstimo com desconto em folha. Ratificando o estudo de Flores (2012) que verificou que os indivíduos que utilizam o cartão de crédito para pagamento das despesas cotidianas revelaram-se mais propensas a se endividar. Salientando que apenas $8,1 \%$ dos respondentes não utiliza esse meio de pagamento nem depende do crédito consignado, evidenciando uma pequena parcela dos servidores que realiza seus pagamentos à vista, sem contrair dívidas.

Tabela 2 - Uso do cartão de crédito

\begin{tabular}{l|c|c|c|c}
\hline \multirow{2}{*}{ Uso do cartão de crédito } & \multirow{2}{*}{ Frequência $(\mathbf{N})$} & \multirow{2}{*}{$\%$} & \multicolumn{2}{|c}{ Depende do crédito (\%) } \\
\cline { 3 - 5 } & & & Sim & Não \\
\hline Não & 15 & 8,1 & - & 8,1 \\
\hline Sim. 1 & 74 & 39,5 & 4,3 & 35,1 \\
\hline 2 & 68 & 37,3 & 37,3 & - \\
\hline 3 ou mais & 28 & 15,1 & 15,1 & - \\
\hline Total & 185 & 100,0 & 56,8 & 43,2 \\
\hline
\end{tabular}

Fonte: dados da pesquisa (2020).

Para complementar a análise quanto ao hábito de uso do cartão de crédito, a Tabela 3 demonstrou que a maior parte dos servidores $(27,03 \%)$ compromete entre 30 e $40 \%$ do orçamento com despesas de cartão de crédito e empréstimo, identificando-se que é gasto, em média, 35\% da renda nesse tipo de despesa, (com um desvio padrão de 1,510). Analisando à luz do limite máximo permitido de $35 \%$ do valor da remuneração empenhados em crédito consignado, no qual os 5\% devem ser reservados exclusivamente para amortização de despesas contraídas no cartão de crédito ou para realizar saques por meio dele, conforme Decreto no ${ }^{\circ} .8 .690 / 2016$ da Presidência da República, a situação dos respondentes não se demonstra tão grave, uma vez que está em conformidade com o percentual determinado.

Porém, considerando que podem existir diversas outras despesas dentro do orçamento das famílias, comprometer uma parcela tão significativa da renda tende a representar um aspecto de risco para o controle dos gastos e alcance do equilíbrio financeiro.

Sendo relevante destacar que $12,97 \%$ dos respondentes relataram comprometer mais de $50 \%$ da renda líquida com o pagamento de cartão(ões) de crédito e empréstimo(s) e 13,51\% afirmaram utilizar entre 40 e $50 \%$ da renda com essas despesas, fato que sinaliza uma situação de endividamento com a necessidade de complemento da renda a partir desse tipo de crédito.

Além de merecer atenção pois o uso do cartão de crédito é um ponto crucial para o endividamento, pelas altas taxas de juros que o chamado rotativo apresenta, passando de $316,7 \%$ a.a. em janeiro para $322,6 \%$ a.a. em fevereiro de 2020, conforme BCB (2020). Também não se pode 
esquecer que ainda há a possibilidade de ocorrerem despesas com cheque especial, prestação de imóvel e veículos somadas a outras despesas domésticas (SOUZA, 2015).

Tabela 3 - Percentual da renda líquida usado com cartão de crédito e empréstimo

\begin{tabular}{l|c|c}
\hline $\begin{array}{l}\text { (\%) Renda líq. com cartão de } \\
\text { crédito/empréstimo }\end{array}$ & Frequência (N) & \% \\
\hline Até $10 \%$ & 20 & 10,81 \\
\hline Entre 10 e $20 \%$ & 30 & 16,22 \\
\hline Entre 20 e $30 \%$ & 36 & 19,46 \\
\hline Entre 30 e $40 \%$ & 50 & 27,03 \\
\hline Entre 40 e 50\% & 25 & 13,51 \\
\hline Acima de 50\% & 24 & 12,97 \\
\hline Total & 185 & 100,00 \\
\hline
\end{tabular}

Fonte: dados da pesquisa, adaptado de Flores (2012).

Ainda em relação ao uso de crédito para o pagamento de despesas usuais, a Tabela 4 evidencia que boa parte dos servidores (40,54\%) afirmou nunca utilizar essa prática, sendo este um resultado relevante uma vez que revela aspectos de um comportamento consciente quanto ao uso do crédito, além de preocupação em não adentrar nesse tipo de crédito bastante caro e favorável ao descontrole financeiro e que pode acarretar em endividamento.

Em contrapartida, 15,68\% dos participantes são sempre dependentes do limite do cartão de crédito ou do cheque especial para quitar despesas cotidianas, seguidos de 20,54\% que afirmam utilizar às vezes. Ratificando os achados de Acordi (2019) que constatou que embora boa parte dos entrevistados tenha dito não utilizar esse tipo de crédito, existe uma parcela de servidores que assume depender eventualmente ou sempre.

Também pelo fato de que "A dependência do crédito para pagar despesas diárias pode sinalizar um descontrole dos gastos, gerando maior propensão ao endividamento" (FLORES, 2012, p. 83). Assim como Silva, Silva Neto e Araújo (2017) perceberam que os entrevistados demonstraram dificuldades quanto ao gerenciamento da renda pessoal e tinham o cartão de crédito como item de maior percentual de dívidas dentro do orçamento.

Nesse contexto, um ponto que merece atenção é a taxa de juros praticada nessas operações, uma vez que segundo o BCB (2020), o cheque especial somou $130 \%$ a.a. e 7,2\% a.m. em fevereiro de 2020, sendo preciso cautela e atenção nas situações em que se utilizar destes produtos. Ainda segundo o BCB (2019), em quantidade de tomadores, o rotativo do cartão de crédito e o cheque especial são uma das modalidades mais utilizadas mesmo com as taxas de juros mais altas entre todas as espécies de crédito, sendo inferiores ao saldo da carteira total que é composta principalmente por crédito habitacional e consignado. 
Tabela 4 - Uso do limite de crédito/cheque especial para pagar gastos cotidianos

\begin{tabular}{l|c|c}
\hline Uso do crédito (cheque especial) & Frequência (N) & $\mathbf{\%}$ \\
\hline Sempre & 29 & 15,68 \\
\hline Às vezes & 38 & 20,54 \\
\hline Raramente & 43 & 23,24 \\
\hline Nunca & 75 & 40,54 \\
\hline Total & 185 & 100,00 \\
\hline
\end{tabular}

Fonte: dados da pesquisa, adaptado de Disney e Gathergood (2011).

Panorama dos Empréstimos Consignados na UFRPE

O primeiro aspecto relevante a ser abordado quanto a descrição do panorama dos empréstimos consignados contratados pelos servidores da UFRPE, se refere ao total de integrantes da instituição. A partir da Tabela 5, nota-se que no decorrer do último quadriênio houve um ligeiro crescimento anual no quantitativo de servidores ativos, registrando um aumento de 86 pessoas ao longo do período, uma variação de 3,74\% e correspondendo a uma média de 21,5 servidores por ano.

Isso pode ser explicado em decorrência do processo de expansão e interiorização da instituição, pela realização de concursos para suprir a demanda tanto de técnico-administrativos como de servidores da carreira do magistério superior das novas Unidades Acadêmicas de Belo Jardim (UABJ), do Cabo de Santo Agostinho (UACSA), de Garanhuns (UAG), atual Universidade Federal do Agreste de Pernambuco (UFAPE), além do campus sede em Recife.

Tabela 5 - Quantitativo de servidores ativos

\begin{tabular}{|c|c|}
\hline Período & Total \\
\hline 2016 & 2.298 \\
\hline 2017 & 2.337 \\
\hline 2018 & 2.348 \\
\hline 2019 & 2.384 \\
\hline
\end{tabular}

Fonte: Adaptado do Relatório de Gestão UFRPE (2018).

Com base na Tabela 6, é possível visualizar esse total de servidores estratificado por carreiras e situação funcional. Percebe-se que o número de técnicos permaneceu praticamente o mesmo, já o quantitativo de docentes e o de aposentados, aumentou. Em relação aos aposentados, com o advento da EC nº 103/2019 que promoveu a reforma da previdência, um temor pela mudança nas regras levou muitos servidores a solicitarem concessão de aposentadoria desde então. 
Tabela 6 - Servidores por carreira e situação funcional

\begin{tabular}{|l|c|c|}
\hline & Maio/2019 & Novembro/2019 \\
\hline Técnico-Administrativos & 1.083 & 1.084 \\
\hline Docentes & 1.286 & 1.300 \\
\hline Aposentados & 903 & 924 \\
\hline Total & 2.369 & 2.384 \\
\hline
\end{tabular}

Fonte: elaborado pela pesquisadora a partir do DDP/UFRPE (2019).

Com o intuito de conhecer o volume de recursos pagos em folha aos servidores, a Tabela 7 demonstra a síntese do Demonstrativo de Despesas com Pessoal (DDP) com o total das despesas em valores brutos (não considerando os descontos obrigatórios por lei nem os descontos facultativos), possibilita também a visualização de um aumento de cerca de $2,43 \%$ em relação aos ativos/aposentados e de $2,34 \%$ no montante total da folha, no comparativo entre os meses de março/2019 e outubro/2019, além do crescimento incontestável em novembro/2019. Nota-se um aumento na comparação dos 3 períodos analisados, sobretudo uma discrepância entre os valores do mês de novembro/2019, em razão de registrar o pagamento automático da segunda parcela do décimo terceiro salário aos servidores, já considerando o abatimento da metade antecipada no primeiro semestre, fazendo com que o valor pago seja praticamente duplicado.

Tabela 7 - Evolução da Folha de Pagamento

\begin{tabular}{|l|l|l|l|}
\hline Situação Funcional & Maio/2019 & Outubro/2019 & Novembro/2019 \\
\hline Ativos/Aposentados & $34.618 .128,27$ & $35.459 .020,83$ & $69.588 .687,24$ \\
\hline Pensionistas & $3.641 .401,97$ & $3.695 .302,69$ & $7.354 .088,92$ \\
\hline Total & $38.259 .530,24$ & $39.154 .323,52$ & $76.942 .776,16$ \\
\hline
\end{tabular}

Fonte: elaborado pela pesquisadora a partir do DDP/UFRPE (2019).

$\mathrm{Na}$ associação realizada entre a folha de pagamentos e os descontos com consignação, na Tabela 8, foram selecionadas as 9 principais instituições financeiras que fornecem crédito consignado para os servidores ativos da UFRPE. Os bancos analisados neste estudo foram: Banco do Brasil S/A, Caixa Econômica Federal, Banco Itaú, Banco Santander, Banco Bonsucesso, Banco PAN, Banco Bradesco, UNICRECI e Banco Banrisul, nos meses de maio/2019, outubro/2019 e novembro/2019, a título de comparação para o estudo. O critério utilizado foi referente às instituições com maiores volumes de recursos tomados em empréstimo consignado pelos servidores.

Merecem destaque os valores descontados nas consignações do Banco do Brasil S/A (com 48,37\% do montante de empréstimos consignados para servidores ativos/aposentados em maio/2019; 39,24\% em outubro/2019 e 39,34\% em novembro/2019), Caixa Econômica Federal (com 22,50\% desse total em maio/2019; 17,34\% em outubro/2019 e 17,37\% em novembro/2019) e Banco Itaú (com 10,79\% do todo em maio/2019; 7,52\% em outubro/2019 e 7,33\% em novembro/2019), pois detém os maiores volumes de recursos em consignação.

Nota-se que o Banco do Brasil S/A, Banco Santander, UNICRECI e demais consignatárias registraram aumento no período analisado, tendo a UNICRECI quase dobrado o volume de recursos. Já a Caixa Econômica Federal, Banco Bonsucesso/Olé e Banco PAN oscilaram no período analisado, enquanto o Banco Itaú, Banco Bradesco e o Banrisul tiveram queda nos 
volumes descontados.

Por fim, ainda em relação a Tabela 8 , o percentual referente às despesas médias com empréstimos consignados nas instituições financeiras analisadas em comparação ao total da folha de pagamentos pode parecer baixo: $5,13 \%$ em maio/2019; $6,32 \%$ em outubro/2019 e 3,22\% em novembro/2019, porém, cabe ressaltar que neste cenário não estão incluídos os demais descontos facultativos como: planos de saúde, previdência privada, mensalidade de sindicatos, amortização com cartões de crédito, nem os descontos obrigatórios como imposto de renda, pensão alimentícia ou previdência social.

Tabela 8 - Valor das Consignações nos bancos com maior volume de empréstimos

\begin{tabular}{|l|c|c|c|}
\hline Bancos & $\begin{array}{c}\text { Ativos/Aposentados } \\
\text { maio/2019 }\end{array}$ & $\begin{array}{c}\text { Ativos/Aposentados } \\
\text { outubro/2019 }\end{array}$ & $\begin{array}{c}\text { Ativos/Aposentados } \\
\text { novembro/2019 }\end{array}$ \\
\hline Banco do Brasil S/A & $949.433,64$ & $971.361,79$ & $973.932,19$ \\
\hline Caixa Econômica Federal & $441,753,44$ & $429.308,83$ & $430.064,32$ \\
\hline Itaú & $211.762,03$ & $186.110,85$ & $181.458,52$ \\
\hline Santander & $202.642,00$ & $250.661,92$ & $255.630,10$ \\
\hline Banco Bonsucesso/Olé & $122.348,53$ & $128.947,53$ & $123.173,09$ \\
\hline PAN & $116.152,96$ & $120.033,06$ & $115.633,85$ \\
\hline Bradesco & $84.888,29$ & $76.718,54$ & $76.723,74$ \\
\hline UNICRECI & $44.092,52$ & $62.201,79$ & $70.827,28$ \\
\hline Banrisul & $43.266,56$ & $42.381,01$ & $36.414,62$ \\
\hline Demais consignatárias & $188.086,75$ & $207.941,40$ & $211.673,03$ \\
\hline Total & $1.962 .673,28$ & $2.475 .666,72$ & $2.475 .530,74$ \\
\hline
\end{tabular}

Fonte: elaborado pela pesquisadora com base no DDP/UFRPE (2019).

\section{Considerações Finais}

O presente artigo buscou fornecer um panorama acerca dos empréstimos consignados contratados pelos servidores Técnico Administrativos em Educação (TAE) ativos da UFRPE pertencentes ao campus Sede da UFRPE que são usuários do crédito consignado, bem como traçar o perfil desses servidores. Para tanto, utilizou-se de dados coletados do extrator de dados da UFRPE, do Demonstrativo de Despesas com Pessoal/UFRPE referente aos meses de maio/2019 e novembro/2019, de dados consultados no Sistema SIAPE e também de informações coletadas através da aplicação do questionário (survey) junto aos servidores técnico-administrativos, objeto do estudo.

Em relação a situação funcional, verificou-se que no período compreendido entre 2016 e 2019 houve um aumento de aproximadamente 4,0\% no quantitativo de servidores em decorrência das ações de expansão e interiorização universitária e de $2,4 \%$ no número de aposentados após o advento da reforma da previdência. Destacando que a categoria dos técnico-administrativos se manteve praticamente inalterada no intervalo entre maio/2019 e novembro/2019, período analisado no estudo. 
No que tange aos recursos pagos em folha de pagamento aos servidores, a partir da análise dos dados do DDP/UFRPE observou-se uma elevação do montante total da folha $(2,5 \%)$ no período compreendido entre maio/2019 e novembro/2019, decorrente do aumento no quantitativo de pessoal e das variações salariais inerentes às carreiras.

Em relação às instituições financeiras passíveis de contratação de crédito consignado, levando em consideração os maiores volumes de recursos tomados em empréstimo pelos servidores, foram identificadas 9 instituições, merecendo destaque em ordem de valores descontados em folha: Banco do Brasil S/A, Caixa Econômica Federal e Banco Itaú. Salientando que o percentual médio de comprometimento da renda dos servidores com despesas em consignação nos bancos analisados foi de 5\%, sem considerar gastos obrigatórios como imposto de renda, contribuição previdenciária e os facultativos a exemplo do plano de saúde, custos com cartão de crédito e empréstimo.

Quanto ao perfil dos 185 servidores participantes da pesquisa, identificou-se que sua maioria é formada por mulheres $(60,54 \%)$ mas que são os homens os maiores usuários do crédito consignado (39,5\%). A faixa etária predominante foi a de 35 a 44 anos $(37,3 \%)$ e verificou-se que à medida que a idade aumenta, diminuem os participantes que afirmam utilizar a consignação em folha de pagamento. Em relação ao estado civil, pouco mais da metade $(51,3 \%)$ era casado(a) e destes $42,2 \%$ revelou ser usuário de empréstimo.

No que tange aos dependentes econômicos, a maior parte dos respondentes $(61,1 \%)$ possui ao menos um, salientando que $22,2 \%$ dos que possuem 1 dependente e $26,5 \%$ dos que possuem 2 dependentes usam crédito consignado, com destaque para os 38,9\% que não possui ninguém que necessite da sua renda e nem tem contrato de consignação.

Acerca da condição de moradia, 39,5\% reside em casa própria e não utiliza crédito consignado. Já dentre os participantes que moram de aluguel (33,5\%) parcela significativa é dependente de consignação (29,7\%). Quanto ao grau de escolaridade, praticamente metade dos servidores possui especialização $(49,7 \%)$ também foi verificado que dentre os servidores com menor nível de graduação a dependência do crédito foi inexistente.

Analisando aspectos de raça foi observado que $44,5 \%$ se define como pertencente à raça branca e dentre eles, $43,2 \%$ afirmou não depender do crédito. Ao passo que $42,7 \%$ denominados como pardos afirmaram fazer uso do empréstimo em consignação.

Em relação ao tempo de serviço, a maioria dos participantes (37,3\%) possui entre 5 e 10 anos de trabalho e não vê no crédito consignado uma opção necessária para socorrer as contas ou financiar algo. Por outro lado, todos os respondentes que possuem mais de 20 anos de serviço $(22,2 \%)$, afirmaram depender do crédito consignado, revelando uma cultura de dependência de crédito observada entre os servidores mais antigos.

A renda predominante encontra-se no intervalo entre 3 e 5 salários mínimos $(31,9 \%)$ e o meio de pagamento mais utilizado é o cartão de débito (39,5\%). Já em relação ao cartão de crédito, a quase totalidade dos servidores $(91,9 \%)$ utiliza esse meio de pagamento, com a parcela predominante de comprometimento da renda entre 30 e $40 \%$, sendo formada por $27,0 \%$ dos participantes. No que tange ao uso do crédito/cheque especial para quitar dívidas do cotidiano, 40,5\% afirmaram não utilizar nunca, por outro lado, 15,7\% dos participantes dependem sempre 
e 20,5\% utiliza às vezes. Ratificando o cartão de crédito como item mais utilizado pelas famílias brasileiras e merecendo atenção por ser o mecanismo responsável pela maior parte do endividamento dos consumidores.

Identificou-se que é gasto, em média, $35 \%$ da renda nas despesas de cartão de crédito e empréstimos. Desse modo, estando de acordo com o limite máximo permitido de $35 \%$ do valor da remuneração empenhados em crédito consignado, no qual os 5\% devem ser reservados exclusivamente para amortização de despesas contraídas no cartão de crédito ou para realizar saques por meio dele, conforme Decreto $n^{\circ}$. 8.690/2016 da Presidência da República, e não revelando discrepância entre a situação dos respondentes e o limite permitido, uma vez que está em conformidade com o percentual determinado.

Entretanto, considerando que podem existir diversas outras despesas dentro do orçamento das famílias, comprometer uma parcela tão significativa da renda tende a representar um aspecto de risco para o controle dos gastos e alcance do equilíbrio financeiro.

Dito isto, compreende-se que a análise efetuada a partir de um corte transversal e temporal na UFRPE demonstra que, embora a maioria dos participantes dependa do crédito consignado e comprometa uma parcela representativa da renda, a maior parte deles afirmou não utilizar as opções de crédito classificadas como as mais onerosas no mercado. Sendo este um resultado relevante, uma vez que revela aspectos de um comportamento consciente quanto ao uso do crédito, além da preocupação em não adentrar nesse tipo de crédito bastante caro, favorável ao descontrole financeiro e que pode acarretar em endividamento.

Revela também que, apesar de ter sido evidenciado um grau de escolaridade significativo pela maioria dos servidores, foram os respondentes com nível mais elevado que representaram maior quantitativo quanto ao uso da consignação em folha de pagamento, sinalizando que este crédito pode estar sendo utilizado para financiamento de imóveis, veículos, investimentos ou ser, de fato, decorrente de um processo de endividamento.

Desta forma, a implementação de medidas que incentivem o desenvolvimento da educação financeira e proporcione um melhor planejamento financeiro são desejáveis e bem-vindas. A exemplo da inclusão de cursos de capacitação para os servidores na área de finanças, gestão do orçamento familiar e ferramentas de melhor uso do crédito.

Por fim, os achados neste estudo servem como base para que seja desenvolvido em outros órgãos, de outras áreas, não apenas federais, mas também a nível estadual ou municipal. Partindo do pressuposto que o plano de carreiras, políticas salariais e concessão de benefícios tende a ser distinta, seria possível traçar um panorama mais amplo acerca desse tipo de consumidor, servidor público independente de sua esfera, que tem na facilidade de acesso, desconto direto das parcelas no contracheque, taxas de juros menores e não exigência de fiador, elementos preponderantes na utilização do crédito consignado em folha de pagamento que tantas vezes é contratado sem o devido planejamento, conduzindo ao temido endividamento. 


\section{Referências}

ACORDI, Francine Patrícia Costa. Finanças pessoais, endividamento familiar e qualidade de vida do servidor. 2019. 144 f. Dissertação (Mestrado profissional em Administração Pública) - Universidade Tecnológica Federal do Paraná. Programa de Pós-Graduação em Administração Pública em rede Nacional, Curitiba, 2019. Disponível em: http://www.profiap.org.br/profiap/ tcfs-dissertacoes-1/utfpr/2019/dissertacao_francine-patricia-costa_2019.pdf. Acesso em: 20 set. 2019.

ALVES, Hélio Heron da Silveira. O Endividamento do Servidor Público no Brasil: O Caso da Universidade Federal do Rio Grande do Sul. Dissertação de Mestrado. UFRGS. Porto Alegre, 2016. Disponível em: https://lume.ufrgs.br/handle/10183/147460. Acesso em 10 jun. 2019.

ASSOCIAÇÃO BRASILEIRA DAS EMPRESAS DE CARTÕES DE CRÉDITO E SERVIÇOS. Notícias, 2019. ABECS. Disponível em: https://agenciabrasil.ebc.com.br/economia/ noticia/2019-06/pagamentos-com-cartao-aumentaram-17-no-primeiro-trimestre. Acesso em: 12 maio. 2020.

BANCO CENTRAL DO BRASIL. Cidadania Financeira - Empréstimo Consignado: características, acesso e uso. Brasília: BCB, 2018. Disponível em: https://www.bcb.gov.br/nor/ relcidfin/docs/art7_emprestimo_consignado.pdf. Acesso em: 6 jun. 2019.

Cidadania Financeira - Gestão de finanças pessoais: caderno de educação financeira. Brasília: BCB, 2013. Disponível em: https://www.bcb.gov.br/pre/pef/port/caderno_cidadania_ financeira.pdf. Acesso em: 17 out. 2019.

Portal de Dados Abertos. Taxa Média de Juros das Operações de Crédito com Recursos Livres - Pessoas Físicas. Brasília: BCB, 2020. Disponível em: https://dadosabertos. bcb.gov.br/dataset/22022-taxa-media-de-juros-das-operacoes-de-credito-com-recursos-livres--pessoas-fisicas---cartao-d. Acesso em: 3 abr. 2020.

Relatório de estabilidade financeira do Banco Central do Brasil, Brasília, volume 18, $\mathrm{n}^{\mathrm{0}}$ 1, abr.2019. Disponível em: https:/www.bcb.gov.br/content/publicacoes/ref/201904/ RELESTAB201904-refPub.pdf. Acesso em: 6 jun. 2019.

BONOMO, Brunno; MAINARDES, Emerson Wagner; LAURETT, Rozélia. Compra não Planejada e Endividamento Pessoal: Uma Análise de Relação. Revista Administração em Diálogo, v. 19, n. 3, p. 49-69, 2017. Disponível em: http://www.spell.org.br/documentos/ ver/46811/compra-nao-planejada-e-endividamento-pessoal--uma-analise-de-relacao-/i/pt-br. Acesso em: 20 set. 2019. http://dx.doi.org/10.23925/2178-0080.2017v19i3.32758.

BRASIL. Decreto nº. 9790/1946 da Presidência da República. Dispõe sobre a consignação de descontos sobre o salário de mutuários das Carteiras de Empréstimos das instituições de previdência social. Brasília: Presidência da República, 1946. Disponível em: http://www. planalto.gov.br/ccivil_03/decreto-lei/1937-1946/Del9790.htm. Acesso em: 7 jun. 2019. 
Decreto $\mathbf{n}^{\mathbf{0}}$. 8690/2016 da Presidência da República. Dispõe sobre a gestão das consignações em folha de pagamento no âmbito do sistema de gestão de pessoas do Poder Executivo federal. Brasília: Presidência da República, 2016. Disponível em: http://www.planalto. gov.br/ccivil_03/ Ato2015-2018/2016/Decreto/D8690.htm. Acesso em: 7 jun. 2019.

Lei $n^{0}$. 1.046/1950 da Presidência da República. Disposição sobre a consignação em folha de pagamento. Brasília: Presidência da República,1950. Disponível em: http://www. planalto.gov.br/ccivil_03/leis/1950-1969/L1046.htm. Acesso em: 8 jun. 2019.

Lei no. 6.445/1977 da Presidência da República. Dispõe sobre consignações em folha de pagamento de servidores civis, ativos e inativos, da Administração Federal direta e das autarquias federais e dá outras providências. Brasília: Presidência da República,1977. Disponível em: http://www.planalto.gov.br/ccivil_03/LEIS/1970-1979/L6445.htm. Acesso em: 8 jun. 2019.

. Lei $\mathbf{n}^{0}$. 8.112/90 da Presidência da República. Dispõe sobre o regime jurídico dos servidores públicos civis da União, das autarquias e das fundações públicas federais. Brasília: Presidência da República,1990. Disponível em: http://www.planalto.gov.br/ccivil_03/leis/ 18112cons.htm._Acesso em: 7 jun. 2019.

Lei n. 10.820/2003 da Presidência da República. Dispõe sobre a autorização para desconto de prestações em folha de pagamento, e dá outras providências. Brasília: Presidência da República,2003. Disponível em: http://www.planalto.gov.br/ccivil 03/leis/2003/ L10.820Compilado.htm. Acesso em: 7 jun. 2019.

Lei no. 11.091/2005 da Presidência da República. Dispõe sobre a estruturação do Plano de Cargos e Carreiras dos Cargos Técnico-Administrativos em Educação, no âmbito das Instituições Federais de Ensino vinculadas ao Ministério da Educação, e dá outras providências. Brasília: Presidência da República,2005. Disponível em: http://www.planalto.gov.br/ccivil_03/_ ato2004-2006/2005/lei/111091.htm. Acesso em: 7 abr. 2020.

. Lei $\mathbf{n}^{0}$ 13.172/2015 da Presidência da República. Altera as Leis n ${ }^{\circ}$ 10.820, de 17 de dezembro de 2003, 8.213, de 24 de julho de 1991, e 8.112, de 11 de dezembro de 1990, para dispor sobre desconto em folha de pagamento de valores destinados ao pagamento de cartão de crédito. Brasília: Presidência da República,2015. Disponível em: http://www.planalto.gov.br/ ccivil_03/_ato2015-2018/2015/lei/113172.htm. Acesso em 7 jun. 2019.

Portaria nº 01/2010 do Ministério do Planejamento, Orçamento e Gestão. Estabelece orientações aos órgãos sobre o processamento das consignações em folha de pagamento do Sistema Integrado de Administração de Recursos Humanos (SIAPE), fixa condições para o cadastramento no âmbito da Administração Pública Federal e dá outras providências. Brasília: Secretaria de Recursos Humanos, 2010. Disponível em: https://www.normas.gov.br/materia/-/ asset_publisher/NebW5rLVWyej/content/id/35364533. Acesso em: 07 nov. 2019.

CAMPARA, Jéssica Pulino; VIEIRA, Kelmara Mendes; CERETTA, Paulo Sérgio. Entendendo a Atitude ao Endividamento: Fatores Comportamentais e Variáveis Socioeconômicas o Determinam? Revista Eletrônica de Ciência Administrativa, v. 15, n. 1, p. 5-24, 2016. Disponível em: http://www.spell.org.br/documentos/ver/44489/entendendo-a-atitude-ao- 
endividamento--fatores-comportamentais-e-variaveis-socioeconomicas-o-determinam-/i/pt-br. Acesso em: 20 set. 2019.

FLORES, Silvia Amélia Mendonça. Modelagem de Equações Estruturais Aplicada à Propensão ao Endividamento: uma análise de fatores comportamentais. 2012. Dissertação de Mestrado(Programa dePós-Graduação em Administração), UniversidadeFederal de Santa Maria, Santa Maria, RS, Brasil. Disponível em: https://repositorio.ufsm.br/bitstream/handle/1/4621/ FLORES\%2c\%20SILVIA\%20AMELIA\%20MENDONCA.pdf?sequence=1\&isAllowed=y. Acesso em 05 nov. 2019.

INSTITUTO BRASILEIRO DE GEOGRAFIA E ESTATÍSTICA. Notícias. Prévia da Inflação. IPCA-15 cai 0,59\% em maio, maior deflação desde o início do Plano Real. 2020. IBGE. Disponível em: https://agenciadenoticias.ibge.gov.br/agencia-noticias/2012-agencia-de-noticias/ noticias/27770-ipca-15-cai-0-59-em-maio-maior-deflacao-desde-o-inicio-do-plano-real. Acesso em: 22 nov. 2019.

INSTITUTO DE PESQUISA ECONÔMICA APLICADA. PEIC. Pesquisa Nacional de Endividamento e Inadimplência do Consumidor. Confederação Nacional do Comércio de Bens, Serviços e Turismo. Setembro/2019. IPEA. [s.1]. Disponível em: http://cnc.org.br/editorias/ economia/pesquisas/pesquisa-de-endividamento-e-inadimplencia-do-consumidor-peic-1. Acesso em: 15 nov. 2019.

LEÃO, Ana Paula Camboim. Empréstimos consignados e endividamento, uma estreita relação entre o(a)s servidores (a)s público(a)s Técnico-Administrativos em Educação. 2016. Dissertação (Mestrado em Consumo, Cotidiano e Desenvolvimento Social) - Universidade Federal Rural de Pernambuco, Recife, 2016. Disponível em: http://www.tede2.ufrpe.br:8080/ tede2/bitstream/tede2/6188/2/Ana\%20Paula\%20Camboim\%20Leao.pdf. Acesso em: 8 jun. 2019.

LIRA, Caetano Correia. Crédito Consignado: cenários no Brasil e diagnóstico na UFPE (2010 a 2012). 2014. Dissertação (Mestrado Profissional em Gestão Pública para o Desenvolvimento do Nordeste ) - Universidade Federal de Pernambuco, Recife, 2014. Disponível em: https:// repositorio.ufpe.br/bitstream/123456789/11720/1/DISSERTA\%C3\%87\%C3\%83O\%20 Caetano\%20Correia\%20Lira.pdf. Acesso em: 8 jun. 2019.

LOPES, Cilene Knauf. Crédito consignado e suas implicações no orçamento familiar: uma análise para servidores da UFV.2018. Dissertação (em Economia Doméstica) - Universidade Federal de Viçosa, Viçosa, 2018. Disponível em: http://www.locus.ufv.br/bitstream/ handle/123456789/22094/texto\%20completo.pdf?sequence=1\&isAllowed=y. Acesso em: 8 jun.2019.

MEDEIROS, Angélica Pott de; OLIVEIRA, Giulia Xisto de; BENDER FILHO, Reisoli. Crédito consignado: segmentos e efeitos econômicos. RACE, Revista de Administração, Contabilidade e Economia, Joaçaba: Ed. Unoesc, v. 17, n. 2, p. 782-810, maio/ago. 2018. Disponível em: http://editora.unoesc.edu.br/index.php/ race. Acesso em: 26 maio 2019.

MOURA, Rivania; OLIVEIRA, Sara Cristina Silva; SILVA, Raila Neris de Oliveira. Crédito 
consignado e seu impacto na vida dos aposentados. In: Encontro Nacional de Pesquisadores em Serviço Social, 16, 2018. Anais... Vitória - ES. UFES, 2018. Disponível em: http://www. publicacoes.ufes.br/ABEPSS/article/view/22717/15199. Acesso em: 23 set. 2019.

PACHECO, Greicy Bainha; CAMPARA, Jéssica Pulino; COSTA JR., Newton Carneiro Affonso da. Traços de personalidade, atitude ao endividamento e conhecimento financeiro: um retrato dos servidores da Universidade Federal de Santa Catarina. Revista de Ciências da Administração, Florianópolis, p. 54-73, dez. 2018. ISSN 2175-8077. Disponível em: https:// periodicos.ufsc.br/index.php/adm/article/view/2175-8077.2018V20n52p54. Acesso em: 03 ago. 2019. doi: https://doi.org/10.5007/2175-8077.2018V20n52p54.

PONCHIO, Mateus Canniatti. The Influence of Materialism on Consumption Indebtedness in the Context of Low Income Consumers From the City of Sao Paulo. [Tese de Doutorado]. Escola de Administração de Empresas de São Paulo da Fundação Getúlio Vargas. São Paulo, p. $175,2006$.

SILVA, Jucyara Gomes; SILVA NETO, Odilon Saturnino; ARAÚJO, Rebeca Cordeiro da Cunha. Educação financeira de servidores públicos: hábitos de consumo, investimento e percepção de risco. Revista Evidenciação Contábil \& Finanças, João Pessoa, v. 5, n. 2, p. 104-120, maio /ago. 2017. Disponível em: https://periodicos.ufpb.br/ojs2/index.php/recfin/article/view/32082. Acesso em: 26 maio 2019. doi:10.18405/recfin20170207.

SOARES, Júnia Rosa; CAVALHERO, Alexandre; TREVISAN, Rafaela Luiza. Pesquisa de diagnóstico: $\mathrm{O}$ endividamento de servidores públicos estaduais com empréstimos consignados e seus efeitos para o programa de cidadania financeira de Santa Catarina. Conselho nacional de secretários de estado da administração. X Congresso CONSAD de Gestão Pública. 2017. Brasília, DF, 5, 6 e 7 de jul. 2017. Disponível em: http://consad.org.br/trabalhos-selecionados-Xcongresso/. Acesso em: 03 nov. 2019.

SOUZA, Dinuarí da Rocha. Endividamento do servidor público: uma análise econômica da situaçãonaUnB. 2015. 86f., il.Dissertação(MestradoProfissional emEconomia)-Universidadede Brasília, Brasília, 2015. Disponível em: http://repositorio.unb.br/handle/10482/18670?locale=fr. Acesso em: 10 jun. 2019.

UFRPE. Comunicado Oficial: impacto dos cortes orçamentários na UFRPE. Recife, 2019. Disponível em: https: http://www.ufrpe.br/br/content/comunicado-oficial-impacto-dos-cortesor\%C3\%A7ament\%C3\%A1rios-na-ufrpe. Acesso em: 13 maio 2020.

UFRPE. Relatório de Gestão do Exercício de 2018 da Universidade Federal Rural de Pernambuco. PROPLAN/UFRPE. Recife, 2019. Disponível em: http://www.ufrpe.br/sites/www.ufrpe.br/ files/RELAT\%C3\%93RIO\%20DE\%20GESTAO\%202018.pdf. Acesso em: 22 set. 2019.

VIEIRA, Kelmara Mendes; FLORES, Silvia Amélia Mendonça; CAMPARA, Jéssica Pulino. Propensão ao Endividamento no Município de Santa Maria (RS): verificando diferenças em variáveis demográficas e culturais. Teoria e Prática em Administração, v. 4, n. 2, p. 180-205, 2014. Disponível em: http://www.spell.org.br/documentos/ver/34455/propensao-ao-endividamentono-municipio-de-sant---. Acesso em: 22 out. 2019. 